\title{
O Discurso e a Prática: o que nos Dizem os Especialistas e o que nos Mostram as Práticas das Empresas sobre os Modelos de Gestão de Recursos Humanos
}

\author{
Beatriz Maria Braga Lacombe \\ Maria José Tonelli
}

\section{Resumo}

A gestão de recursos humanos tem passado por grandes transformações nestes últimos anos, em função da necessidade das empresas de incrementar a sua capacidade competitiva para enfrentar a concorrência dos mercados globalizados. O objetivo deste trabalho é comparar alguns resultados obtidos a partir de pesquisa realizada junto a 100 empresas da região da Grande São Paulo, bem como as idéias de 14 especialistas (acadêmicos e consultores), de diferentes regiões do país, sobre o que define e quais são as funções da área de recursos humanos, com as tendências e os conceitos apontados na literatura nacional e internacional sobre o tema. O principal interesse do trabalho é verificar se ainda há grande distância entre o discurso e a prática. As empresas pesquisadas foram classificadas em três grandes grupos: (1) aquelas que ainda mantêm uma abordagem mais operacional; (2) aquelas que já adotam uma abordagem estratégica; e (3) aquelas que se aproximam mais de uma abordagem competitiva. $\mathrm{O}$ estudo mostra ainda que há grande diversidade no pensamento dos especialistas, o que contribui, na nossa opinião, para a heterogeneidade encontrada nas práticas de gestão de recursos humanos entre as empresas nacionais.

Palavras-chaves: modelos de gestão de pessoas; administração estratégica de recursos humanos; administração de recursos humanos para a vantagem competitiva.

\begin{abstract}
The globalization of markets has put enterprises under a lot of pressure to increase their competitiveness and human resource management has been greatly impacted by such changes. The main objective of this paper is to compare some of the results obtained in a research project conducted with 100 enterprises in the Great São Paulo area, Brazil, as well as the ideas voiced by 14 experts (academics and consultants) from all over the country, about what defines and which are the main functions of the human resources area, with the concepts and trends most discussed in the national and international literature. The main interest of this work is to verify the existence of a gap between discourse and practice. The research data suggest the formation of three groups of enterprises: (1) those who still maintain an operational approach to the human resources area; (2) those that adopt a strategic approach and (3) those who get closer to the management for competitiveness approach. The study also shows great diversity among the experts thinking, which enhances even further, in our opinion, the found heterogeneity of the human resources practices.
\end{abstract}

Key words: people management models; strategic human resource management; human resource management for competitive advantage. 


\section{INTRODUÇÃO}

A revisão da literatura sobre a administração de recursos humanos (ARH) nas últimas décadas deixa claro um descompasso entre a percepção de problemas e identificação de tendências pelos diversos autores e a prática desta administração, principalmente em relação às empresas brasileiras, que é o interesse deste trabalho. O movimento da administração de pessoal para a área de recursos humanos é bastante conhecido, tendo ocorrido em épocas diversas para países diferentes, ou mesmo para diferentes setores da economia. O conceito de administração estratégica de recursos humanos surgiu no início da década de 80 nos Estados Unidos, tendo sido reconhecido como necessário, no Brasil, pelas organizações, apenas alguns anos depois. Pesquisas mostram como este modo de se pensar recursos humanos era ainda incipiente no final da década de 80 e, como, na década de 90, a maioria das empresas ainda não adotava muitas das práticas recomendadas por autores estrangeiros e nacionais.

Este trabalho pretende ser uma contribuição para a discussão da teoria e da prática no contexto brasileiro e foi organizado da seguinte maneira: na primeira parte, é apresentada uma breve revisão de autores que discutem a evolução do papel da área de gestão de recursos humanos; a segunda parte traz um panorama de como tem sido, na duas últimas décadas, a prática das empresas brasileiras; na terceira parte, é apresentada sucinta descrição da pesquisa realizada com especialistas da área e empresas brasileiras; na última parte, alguns dos resultados são questionados e sugerem-se indicações para pesquisas futuras.

\section{A Administração estratégica de Recursos Humanos}

O conceito de planejamento estratégico para recursos humanos (PERH) surgiu no início da década de 80 , tendo sido desenvolvido, inicialmente, através de duas abordagens. A primeira, conhecida como o Michigan Concept, desenvolvido por Tichy e seus colaboradores, define PERH como a ligação de missão, estratégia, estrutura e RH. Põe mais ênfase temporal e quantitativa na missão e na estratégia, RH se adequando àqueles fatores. O PERH consiste, basicamente, em desenvolver estrategicamente quatro fatores: seleção, avaliação, remuneração e desenvolvimento. A segunda abordagem, o Harvard Concept, enfatiza mais a perspectiva da gestão da administração de recursos humanos, ressaltando 
o papel não só de adaptador, mas de interventor no planejamento estratégico. São quatro as áreas-chaves para a determinação de políticas de RH: grau de influência do empregado (participação); o fluxo de RH (recrutamento, utilização e demissão); o sistema de recompensas; e os sistemas de trabalho (organização do trabalho). Estas áreas são afetadas pelos interesses dos stakeholders, onde se incluem os empregados, e por fatores situacionais, como características da força de trabalho, filosofia da administração, estratégias de negócios, mercado de trabalho, sindicatos etc. As decisões têm efeitos imediatos em termos de comprometimento, competência, congruência e custo, e também de longo prazo, como o bem-estar dos empregados, efetividade organizacional e bem-estar social. As políticas têm efeitos circulares, o que deve ser reconhecido ao serem traçadas e implementadas (Staehle, 1990).

O papel estratégico a ser desempenhado passa a ser repensar as atividades próprias da área de $\mathrm{RH}$ em termos estratégicos, ou seja, de forma a integrar os objetivos de longo prazo da organização, as variáveis relevantes do ambiente e as necessidades decorrentes em termos de pessoas. Devana, Fombrun e Tichy (1984) descrevem como devem ser os subsistemas de seleção, avaliação, recompensas e desenvolvimento, a partir da ótica estratégica e, principalmente, a partir da visão que a organização tem do tipo de contrato que quer estabelecer com seus empregados. Esta visão compreende elementos como os seguintes: a relação que a organização quer estabelecer com o empregado, se limitada a recompensar desempenho ou se baseada na troca de comprometimento por qualidade do trabalho a ser realizado; o grau de participação que se pretende dos empregados; a ênfase dada ao recrutamento, se interno ou externo, quando necessário; por fim, se o desempenho será baseado e avaliado de forma individual, ou em equipes, ou, ainda, alguma mistura entre os dois. É esta visão que vai definir, em princípio, como os subsistemas serão administrados. Estes conceitos encontram correspondência no que Fisher (1998, p. 47) denomina de modelo de gestão de pessoas, que não se restringe apenas ao caráter instrumental da gestão de pessoas, mas engloba também um componente real e dinâmico, "uma lógica de atuação que é ao mesmo tempo política, social, ideológica e comportamental". O modelo, ao simplificar a realidade, orienta a decisão e a ação.

Apesar de reconhecerem que organizações diferentes podem vir a adotar visões diferentes, os autores descrevem as vantagens de se adotar alguns conceitos no planejamento estratégico de recursos humanos; entre eles, há a idéia de que a seleção deve privilegiar o recrutamento interno, pois "bons gerentes [...] não nascem, mas são feitos" (Devana, Fombrun e Tichy, 1984, p. 45). A necessidade de se formarem gerentes dentro da organização, ao invés de sempre buscá-los no mercado, aliada à necessidade de se planejar onde e quando alocar tais executivos, vai gerar uma ênfase no desenvolvimento de pessoas, o que deverá 
refletir-se em todos os outros subsistemas de recursos humanos, como seleção, avaliação, remuneração e treinamento.

Conforme ressalta Albuquerque (1987), a necessidade de se pensar em recursos humanos de forma estratégica decorreu, principalmente, do reconhecimento da importância de se considerar o ambiente externo na formulação das estratégias de negócios, e da existência de um gap entre as necessidades previstas para a implantação destas estratégias e as realidades que as organizações enfrentavam em termos de pessoas para implantá-las. Springer e Springer (1990) avaliam que a prática de recursos humanos nos anos 90 seria basicamente focada no elenco seguinte.

- Recrutamento: ênfase no recrutamento interno como melhor forma de adequação aos objetivos estratégicos.

Análise de funções: cada vez mais deveria ser utilizada, sob a forma de descrição, especificação e avaliação de funções, com a finalidade de fornecer informações para todo o espectro das atividades de $\mathrm{RH}$, e não mais como controle ou imposição de tarefas predeterminadas.

- Treinamento e desenvolvimento: os autores previam grande crescimento da função treinamento. In-house training para o pessoal operacional, uma vez que a proximidade do local de trabalho permitiria a resolução de problemas específicos. Já para o nível gerencial, previam o foco no desenvolvimento de competências, que compreendem conhecimento, habilidades e atitudes, por meio de treinamentos tanto técnicos como comportamentais.

Albuquerque (1992) assinala como deverão ocorrer mudanças nas relações de trabalho, graças à intensificação da competitividade. Nova concepção de empresa competitiva começa a ser desenhada. Esta concepção transformada da organização, que tem como objetivo maior atender aos interesses dos stakeholders, prevê como políticas de recursos humanos a manutenção das pessoas na organização, mas de modo flexível, com intercâmbio de carreiras e funções, sendo o foco colocado no desempenho, aliado a incentivos grupais, o que favorece a atuação das equipes. Fica clara, portanto, a importância da preparação destes empregados para funções presentes e futuras, além das habilidades de se trabalhar em grupos.

Nos anos 90, Anthony, Perrewé e Kacmar (1996) indicam que a estratégia de $\mathrm{RH}$, além de reconhecer os impactos do ambiente, deve ter um foco no longo prazo, em escolha e processo decisório, considerar todo o pessoal (e não apenas os operacionais) e ser integrada com a estratégia corporativa. Os autores indicam que as funções de recursos humanos devem ser alinhadas à estratégia da empresa, mas sugerem que "todos os gerentes devem ser vistos como gerentes 
de recursos humanos" (Anthony, Perrewé e Kacmar, 1996, p. 17). Os gerentes, mesmo os de linha, começam a ser vistos como responsáveis pela utilização eficiente e eficaz de seus subordinados, sendo ao profissional de RH designado o papel de aconselhamento e coordenação dos esforços para que os gerentes possam desempenhar este novo encargo. Uma interdependência de gerentes e profissionais de RH deve desenvolver-se, na medida em que os gerentes se tornam cada vez mais capazes de resolver problemas de pessoas, ao passo que o profissional de RH se torna cada vez mais capaz de compreender as diversas dinâmicas que cada área envolve.

Siehl e Bowen (1997) identificam outro papel para RH, ligado às mudanças por que passam as relações de trabalho. De acordo com os autores, o antigo contrato psicológico existente entre empregado e empresa, que previa relação duradoura e emprego para a vida toda, tornou-se obsoleto e vem ruindo com a flexibilização das relações de trabalho e o surgimento de novas formas de se trabalhar. É preciso, portanto, redefinir e comunicar um novo contrato psicológico. O profissional de RH deve trabalhar com a alta administração o conteúdo deste contrato e depois mostrá-lo aos trabalhadores. Os autores vêem também como grandes desafios para RH, a facilitação do trabalho entre trabalhadores separados fisicamente e a promoção da flexibilidade entre as pessoas, acostumadas a outro modo de agir.

Fisher (1998) aponta um novo significado assumido pela ARH a partir dos anos 90: a ARH como vantagem competitiva. Com a perspectiva voltada para o negócio da empresa, começa a ser levantado o papel das pessoas para a obtenção da competitividade. Se a estratégia é a diferenciação e a obtenção de vantagem competitiva, cabe à ARH garantir que as pessoas sejam também fonte de vantagem competitiva. As empresas precisam buscar formas novas e criativas de gestão; à ARH cabe transmitir as estratégias às pessoas e transformá-las em agentes de competitividade. Com base nas tendências e desafios apontados por Ulrich (1998), o autor atribui quatro funções principais à área de recursos humanos: as funções estratégicas, a competitiva, a função de promover e auxiliar os processos de mudança e a função responsável pelo envolvimento dos empregados com a empresa. Para o autor, o papel da ARH se amplia, conforme ilustra o Quadro 1. 


\section{Quadro 1: ARH Estratégico x Vantagem Competitiva}

\begin{tabular}{|l|l|l|}
\hline \multicolumn{1}{|c|}{ RH como } & \multicolumn{1}{|c|}{ Estratégico } & \multicolumn{1}{c|}{ Vantagem Competitiva } \\
\hline $\begin{array}{l}\text { Perído } \\
\text { aproximado }\end{array}$ & 1980-1990 & 1990 - \\
\hline $\begin{array}{l}\text { Condições } \\
\text { que propiciam } \\
\text { surgimento }\end{array}$ & $\begin{array}{l}\text { Reconhecimento/importância } \\
\text { dos fatores do ambiente; } \\
\text { necessidade de vincular } \\
\text { gestão de pessoas às } \\
\text { estratégias organizacionais. }\end{array}$ & $\begin{array}{l}\text { Maior competitividade; necessidade de } \\
\text { diferenciação; pessoas vistas como } \\
\text { recursos para vantagem competitiva. }\end{array}$ \\
\hline Papel & $\begin{array}{l}\text { Adaptação das pessoas às } \\
\text { necessidades estratégicas. }\end{array}$ & $\begin{array}{l}\text { Transmissão das estratégias às pessoas } \\
\text { e transformá-las em agentes de } \\
\text { competitividade. }\end{array}$ \\
\hline $\begin{array}{l}\text { Funções e } \\
\text { contribuições }\end{array}$ & $\begin{array}{l}\text { Motivar empregados, manter } \\
\text { segurança e bom ambiente, } \\
\text { garantindo envolvimento. }\end{array}$ & $\begin{array}{l}\text { Estratégica, competitiva, focada na } \\
\text { mudança e no envolvimento dos } \\
\text { empregados. }\end{array}$ \\
\hline $\begin{array}{l}\text { Principais } \\
\text { atividades }\end{array}$ & $\begin{array}{l}\text { Treinamento; recrutamento } \\
\text { interno; desenvolvimento; } \\
\text { busca de práticas ideais; } \\
\text { terceirização; } \\
\text { descentralização. }\end{array}$ & $\begin{array}{l}\text { Administrar rede de agentes } \\
\text { organizacionais: gerentes, parceiros } \\
\text { internos e externos; administrar } \\
\text { programas que dependem do } \\
\text { comportamento das pessoas; criar } \\
\text { instrumentos de gestão para as } \\
\text { pessoas; mensurar impactos de RH; } \\
\text { manutenção da capacidade intelectual } \\
\text { da organização; orientação para um } \\
\text { desenvolvimento integrado. }\end{array}$ \\
\hline
\end{tabular}

Fonte: adaptado de Fisher (1998).

\section{A ARH No BrasiL}

O caso brasileiro é muito peculiar, conforme já apontado por diversos autores (Albuquerque, 1987; Dutra, 1993; Fisher, 1998). Apesar da necessidade de se tratar a ARH como estratégica já ter aparecido na literatura no início nos anos 80 (Barbosa [1981], Bertero [1982], entre outros), a implementação da prática deuse com anos de atraso, em função, principalmente, das condições macroeconômicas vigentes, que não evidenciavam a necessidade das mudanças preconizadas.

No final da década, duas pesquisas confirmam a situação apenas incipiente da ARH estratégica. Na primeira, Dutra (1987), ao estudar os profissionais da área 
de recursos humanos, admite que, apesar de terem encontrado grande espaço para a ação dentro das empresas brasileiras, em função de uma situação favorável, onde aumentou a complexidade organizacional do país, promovendo um aquecimento do mercado interno e da intensificação das pressões dos trabalhadores, o grupo estudado ainda estava mais preocupado com problemas de relações sindicais do que com o redesenho da área em si, sua estrutura e seus instrumentos. Em geral, a maior preocupação das áreas de $\mathrm{RH}$, recém instaladas nas empresas, se restringia aos aspectos operacionais do trabalho.

Na segunda pesquisa, Albuquerque (1987, p. 11) afirma que "parece haver um crescente entendimento entre pesquisadores e profissionais de Administração de Recursos Humanos do caráter estratégico de que se revestem suas atividades", caráter este devido, em grande parte, ao aumento da complexidade do ambiente externo e da influência de suas variáveis sobre a organização. $\mathrm{O}$ autor aponta a necessidade de profissionais multidisciplinares, com capacidade de reconhecer mudanças e interpretar seus impactos nas políticas da empresa de curto e longo prazo. Em pesquisa realizada com 168 empresas do Sudeste e Sul do país, o autor comenta que "muito embora não se evidencie uma ligação forte entre planejamento estratégico e planejamento estratégico de Recursos Humanos, já se configura uma tendência de aceitação do planejamento estratégico de Recursos Humanos, por parte da alta administração" (Albuquerque, 1987, p. 213). Na maioria das empresas pesquisadas, o executivo da área era envolvido de alguma forma no processo de formulação das estratégias organizacionais.

Portanto nota-se um atraso de quase uma década entre o discurso da literatura e a prática no Brasil; entretanto a década de 90 é marcada por profundas transformações no cenário econômico, afetando diretamente o padrão de competitividade das empresas brasileiras. $\mathrm{O}$ foco anterior das preocupações era muito mais como gerir a área financeira, dada a necessidade de convivência com as altas taxas de inflação e os inúmeros planos e choques econômicos, produzindo empresas inchadas, com pouco controle sobre custos, desperdícios e até mesmo sobre a eficiência da produção. Assim, nos primeiros anos da década de 90, conforme observa Fisher (1998), as estratégias adotadas pelas empresas para enfrentar os novos cenários, eram tipicamente reativo-defensivas, concentradas no enxugamento e redução de custos. Duas pesquisas datadas de 1995 refletem o que estava acontecendo com a ARH, como resposta a estas transformações.

Venosa e Abbud (1995), em pesquisa realizada junto a 98 dirigentes de empresas, mostram que as funções vistas como mais importantes, dentro da área de recursos humanos, eram recrutamento e seleção, benefícios, treinamento e de departamento pessoal, as rotinas burocráticas. O planejamento de carreira formalizado não existia em $69,89 \%$ das empresas pesquisadas; $60,22 \%$ não tinham 
planejamento de pessoal; 50,54\% não faziam avaliação de desempenho; $31,18 \%$ não tinham serviço social e $31,18 \%$ não faziam pesquisa de salários. Privilegiavam-se, portanto, as atividades mais burocráticas, valendo-se ainda do princípio de que, desde que se recrute a pessoa certa para o lugar certo, pagando-lhe um salário justo e treinando-a adequadamente, os problemas com pessoal estarão resolvidos. Corroborando esta hipótese, os autores encontraram que, na opinião dos dirigentes, as empresas não possuem políticas de RH bem estruturadas e aplicadas, o que dava margem, então, aos procedimentos informais.

A pesquisa de Curado, Wood e Lins $(1995$, p. 69) junto aos dirigentes da área de recursos humanos de 100 empresas também mostra que "a maior parte das empresas pesquisadas tem a atuação de sua área de RH voltada para questões trabalhistas e operacionais". As políticas e práticas de RH, ainda pouco sofisticadas e diversificadas, também não são claramente formuladas ou sistematizadas. A maior parte das empresas (61\%) ainda era estruturada como departamento pessoal (DP), sendo as atividades e funções pertinentes à área centralizadas neste departamento. Das funções previstas por um PERH anteriormente descritas, o recrutamento interno era pouco utilizado (12\%); o treinamento era pouco privilegiado para todos os níveis de empregados; e a administração de carreiras também era pouco expressiva nas empresas com estrutura de DP, revelando falta de preocupação com a tradução de planejamento estratégico em ações e, portanto, com o longo prazo. É interessante ressaltar que apenas $35 \%$ das empresas tinham planejamento estratégico formalizado, sendo a participação da área de RH mais restrita às fases de fornecimento de informações e execução.

Dos resultados das duas pesquisas, pode-se depreender que, apesar do reconhecimento da necessidade de se tratar a ARH de forma estratégica, como se indica na pesquisa de Albuquerque (1987), na prática a participação da área se restringia à administração dos processos operacionais. As atividades que caracterizam uma ARH estratégica, como o treinamento, o recrutamento interno, a busca de práticas ideais e a utilização de terceirizações e descentralização de processos, ainda eram pouco difundidas. Enquanto as pesquisas mostram o pouco desenvolvimento da ARH estratégica nas empresas brasileiras surge, durante a década de 90, o conceito de ARH como vantagem competitiva, que amplia ainda mais o leque das atividades necessárias a um gerenciamento de pessoas.

Fisher (1998) reconhece que a partir de 1995 começa a surgir nova tendência nas estratégias adotadas pelas empresas brasileiras, em função do reconhecimento da importância que passa a ter o cliente, diante de ambientes tão competitivos. $\mathrm{O}$ autor mostra como esta mudança de foco impactou não apenas os processos produtivos, mas levou as empresas a repensar os processos de pessoas, a exemplo do que já vinha acontecendo nos outros países. Entre os programas 
e técnicas mais adotados destacam-se os seguintes: planejamento estratégico, implementação do trabalho em equipe, gestão da qualidade total, aquisição de equipamentos automáticos, planejamento das necessidades de materiais (MRP), programa de conservação de energia, redução do lead time, terceirização, entre outros. Pode-se perceber quanto estes e outros programas que se seguiram são dependentes do envolvimento e da atuação de pessoas, para que possam ter sucesso, forçando a ARH a adotar novas perspectivas.

\section{A Pesquisa}

A pesquisa realizada em 1999 teve por objetivo verificar junto a 100 empresas da Grande São Paulo, como a área de recursos humanos está conduzindo suas práticas, onde foram considerados os seguintes aspectos: como está estruturada a área de $\mathrm{RH}$, quais as políticas e práticas mais utilizadas, o grau de planejamento e estruturação das atividades e o envolvimento da área de RH com programas de mudança organizacional. As empresas foram selecionadas aleatoriamente pelo índice Dun\&Bradstreet 10.000. O questionário continha 64 questões sobre os itens acima mencionados, sendo a maioria composta de questões fechadas. No final, foram feitas duas questões abertas sobre as principais preocupações da área e as perspectivas de mudança que estavam sendo vislumbradas pelos profissionais entrevistados, que eram, em geral, os responsáveis pela área, como gerentes, supervisores, superintendentes e diretores. As entrevistas foram realizadas durante o ano de 1999.

Em paralelo, uma pesquisa semelhante foi realizada com 14 especialistas da área, entre acadêmicos e consultores, de diferentes regiões do país, em 1998 e 1999. As entrevistas com os especialistas foram gravadas e transcritas e o material, que será apresentado, resulta de um recorte efetuado a partir de duas questões introdutórias: que é que define a área de RH, na sua concepção? Quais as funções que deveriam ser realizadas pela área de RH?

\section{A Pesquisa com Acadêmicos e Consultores}

Uma síntese das respostas dos especialistas está condensada no Quadro 2. Foram extraídos trechos dessas entrevistas que melhor resumiam a opinião dos entrevistados, com o objetivo de identificar como cada um definia os conceitos relevantes para a área e que poderiam ser associados ao modelo de gestão de pessoas proposto por Fisher (1998), anteriormente descrito. 


\section{Quadro 2: Resumo das Definições e Funções da Área de RH para 14 Entrevistados}

\begin{tabular}{|c|c|}
\hline & Definição e função da área de $\mathrm{RH}$ para os entrevistados \\
\hline 1 & $\begin{array}{l}\text { "A área de RH seria em torno de uma política, de desenvolvimento de pessoas, } \\
\text { preparação para se preocupar não só com a produtividade, mas com a qualidade } \\
\text { de vida desses profissionais que trabalham com a empresa. Eu vou dizer assim: pôr } \\
\text { as pessoas certas nos lugares certos". }\end{array}$ \\
\hline 2 & $\begin{array}{l}\text { "Você seleciona, você recruta, mas isso pode ser feito até por uma outra, } \\
\text { pode ser terceirizado. Então, eu acho o seguinte: o indivíduo entrando na } \\
\text { organização, esta pessoa passa por três áreas fundamentais, que seriam o que, } \\
\text { desenvolvimento e aí empregam todas e significam as mais complexas fórmulas. } \\
\text { A questão da remuneração, esta remuneração significando salário, beneficios e o } \\
\text { aspecto simbólico do reconhecimento no trabalho. E o terceiro eu diria que é a } \\
\text { questão do controle, que seria uma forma de como este indivíduo é visto dentro } \\
\text { da organização e isso está muito ligado ao modelo de gestão". }\end{array}$ \\
\hline 3 & $\begin{array}{l}\text { "Você tem, de um lado, a cúpula da organização que está definindo as grandes } \\
\text { diretrizes estratégicas e a área de recursos humanos, na relação com este ator; } \\
\text { ela tem umpapel importante não só de participar, mas de dar o suporte metodológico } \\
\text { de informação, de tendência de mercado, de análise da realidade organizacional } \\
\text { nessa reflexão estratégica da organização". }\end{array}$ \\
\hline 4 & $\begin{array}{l}\text { "Hoje é uma área que tenta estabelecer e botar um pé na equação estratégica de } \\
\text { negócios da empresa, criando argumentos de que recursos humanos são mais } \\
\text { importantes. Não consegue convencer a liderança da empresa e hoje se ocupa de } \\
\text { uma tarefa importante que é criar condições de promover o auto-desempenho". }\end{array}$ \\
\hline 5 & $\begin{array}{l}\text { "Olha, eu tenho uma visão de que a área de RH deve ter uma preocupação global, } \\
\text { geral e estratégica com a gestão das pessoas nas organizações. O primeiro } \\
\text { eixo para mim, seria o eixo voltado para a questão do desempenho no sentido } \\
\text { de como garantir um sistema de trabalho de alto desempenho, de desempenho } \\
\text { satisfatório e aí eu acho que aí temos uma grande função e uma grande importância. } \\
\text { Eu acho que o segundo grande eixo é de como ajudar a organização, a gestão } \\
\text { e os gerentes a lidar com as trocas do indivíduo com a organização. E eu vejo } \\
\text { um terceiro eixo e eu nem sei que rótulo vou dar a ele, mas que seria uma } \\
\text { visão mais prospectiva do futuro em te rmos do elemento humano na } \\
\text { organização". }\end{array}$ \\
\hline 6 & $\begin{array}{l}\text { "Eu acho que esta área de RH ela é uma área estratégica e uma área de apoio e no } \\
\text { passado ela foi sempre vista mais como uma área de apoio, o que foi um erro. Então } \\
\text { esta área é uma área que permeia toda a empresa e ela tem que ser vista como tal". }\end{array}$ \\
\hline 7 & $\begin{array}{l}\text { "Então o pessoal de RH é fundamental no sentido de captar, desenvolver, de } \\
\text { preparar as pessoas para serem geridas e para permitirem à organização } \\
\text { sobreviver. Agora, que RH promova o desenvolvimento dos gestores para que } \\
\text { eles sejam capazes de gerir gente, beleza". }\end{array}$ \\
\hline
\end{tabular}




\begin{tabular}{|c|c|}
\hline 8 & $\begin{array}{l}\text { "Principalmente, que eu vejo, é o desenvolvimento e a educação e quando coloco } \\
\text { educação, coloco educação no sentido de proporcionar uma aprendizagem, que é } \\
\text { fundamental, ou seja, a gente não fala mais em treinamento, a gente fala em } \\
\text { desenvolvimento, a gente fala na possibilidade de ser educado dentro de uma } \\
\text { organização para que pouco você possa conseguir o conhecimento global". }\end{array}$ \\
\hline 9 & $\begin{array}{l}\text { "Eu acho que a área de } \mathrm{RH} \text { é responsável pela gestão de desempenho das } \\
\text { pessoas. Eu acho que a área de } \mathrm{RH} \text { tem que estar hiperintegrada na } \\
\text { estratégia da empresa. Em que a empresa está fazendo no curto e no longo } \\
\text { prazo". }\end{array}$ \\
\hline 10 & $\begin{array}{l}\text { "A área de RH eu defino como a área que é a grande responsável por trazer e } \\
\text { manter bons profissionais, sejam eles de qualquer nível, e pôr para dentro da } \\
\text { empresa e se preocupar com o desenvolvimento dele, colocar as pessoas certas no } \\
\text { lugares certos, fazer um acompanhamento se ele está com uma faixa salarial } \\
\text { adequada ao perfil que ele procura, ao que ele quer dar em troca da empresa. } \\
\text { Desde o recrutamento e seleção de todos os níveis dentro da empresa, a parte de } \\
\text { desenvolvimento e de treinamento desses profissionais para estarem sempre } \\
\text { atualizados, a parte de remune ração para que eles estejam realmente } \\
\text { trabalhando e se desenvolvendo bem e recebendo os salários compatíveis } \\
\text { com o que eles estejam fazendo. Eu acho que também cuidar de um papel } \\
\text { social da relação com a comunidade e com a sociedade". }\end{array}$ \\
\hline 11 & $\begin{array}{l}\text { "Ela é uma função facilitadora que tem por objetivo prover recursos e condições } \\
\text { sempre e enquanto facilitador para a produção do desempenho, tendo em vista dois } \\
\text { aspectos: a produção do desempenho tendo em vista o desempenho exigido pelo } \\
\text { negócio e pelo crescimento psicológico do profissional. Então é uma área } \\
\text { facilitadora que produz recursos e condições para a produção do desempenho } \\
\text { exigido pelo negócio e exigido pelo crescimento psicológico das pessoas". }\end{array}$ \\
\hline 12 & $\begin{array}{l}\text { "Eu acho que até seis ou oito anos atrás existia muito mais uma perspectiva de } \\
\text { trabalhos muito técnicos, que a área de RH estava muito relacionada às atividades } \\
\text { tradicionais do departamento pessoal. Eu posso listar isso como salários, } \\
\text { pagamentos, legislação e coisas neste sentido. Eu acho que hoje existe uma } \\
\text { perspectiva muito mais globalizante preocupada justamente com as mudanças que } \\
\text { estão ocorrendo e as, digamos, novas exigências em função de questões como } \\
\text { qualificação do trabalhador em relação à questões condicionantes, } \\
\text { multifuncionalidade, politecnia e coisas neste sentido. Existe uma perspectiva hoje } \\
\text { de trabalhar com recursos humanos muito mais no sentido de políticas de recursos } \\
\text { humanos, de estratégias de trabalhos com recursos humanos". }\end{array}$ \\
\hline 13 & $\begin{array}{l}\text { "Antes de falar em funções, eu prefiro falar da filosofia, antes porque tudo } \\
\text { decorre daí. Qual é a filos ofia desta empresa? Como é que ela vê as } \\
\text { pessoas? Então, em função de como ela vê as pessoas, ela vai definir o papel } \\
\text { das pessoas e a recompensa a ser oferecida pela empresa". }\end{array}$ \\
\hline 14 & $\begin{array}{l}\text { gada de gerar e produzir um comportamento } \\
\text { rente com o negócio na empresa". }\end{array}$ \\
\hline
\end{tabular}


Do Quadro 2, de acordo com as tendências indicadas no modelo de Fisher (1998), é possível verificar que as idéias dos especialistas podem ser reunidas em dois grandes grupos. O primeiro grupo $(1,2,7,8,9,10,12,14)$, mais numeroso, possui uma visão da área de RH como estratégica. O segundo grupo $(3,4,5,6$, $11,13)$ apresenta uma visão da área de RH mais próxima do conceito de modelo de gestão para vantagem competitiva. É possível verificar que, mesmo dentro da comunidade de especialistas, os conceitos diferem bastante.

\section{A Pesquisa com as Empresas}

Os resultados da pesquisa mostram uma evolução na prática da $\mathrm{ARH}$, se comparada às pesquisas mencionadas neste trabalho. O Quadro 3 , a seguir, mostra um resumo de como estão sendo realizadas as principais funções típicas de uma ARH estratégica.

Os resultados do Quadro 3 configuram um movimento bem definido em direção a uma ARH estratégica, conforme as características desta abordagem apresentadas no Quadro 1. Apesar de a maior parte das empresas ainda ter as atividades de RH centralizadas em um único departamento, já é expressivo o número de empresas que adotam uma estrutura mista, descentralizando algumas funções, como seleção e treinamento. A terceirização está sendo mais utilizada. $\mathrm{O}$ recrutamento interno aparece como uma das mais fortes fontes de recrutamento. $\mathrm{O}$ treinamento também é muito mais expressivo que nas pesquisas anteriores. Essas duas tendências juntas sugerem um investimento maior na manutenção e no desenvolvimento de um quadro de pessoas. A administração de carreiras mostra preocupação e abertura para o ambiente externo. O planejamento estratégico é adotado por $59 \%$ das empresas visitadas. Em $90 \%$ destas, a área de RH participa do planejamento estratégico, sendo a sua participação muito significativa tanto no fornecimento de informações (76\%), como na execução dos programas $(71 \%)$, mas sendo menor a atuação no processo de planejamento propriamente dito (56\%). Esses números parecem indicar que, apesar de já estar mais perto da alta direção, de já ter mais responsabilidade pelos processos decisórios, pelas políticas e sua implantação, a ARH parece ter papel ainda mais de seguidor e adaptador dos recursos humanos às políticas, do que propriamente um interventor ou criador conjunto de estratégia organizacional.

Em suma, os dados quantitativos sugerem uma evolução na ARH estratégica. A abordagem estratégica não está totalmente implementada, mas a maioria das empresas já adotou um ou outro conceito, numa tentativa de mudar a administração de pessoas. A tendência à manutenção e maior treinamento dos empregados se contrapõe à ênfase em redução de custos apontada nos primeiros anos da década passada. A fase mais aguda dos cortes e downsizings provavelmente já 
foi efetuada, ficando a percepção de que, agora, é preciso fazer mais com menos gente. A ARH como vantagem competitiva, tendência apontada pela literatura, será que já está ganhando terreno nas empresas brasileiras?

\section{Quadro 3: Resumo da Prática das Principais Funções da ARH em 100 Empresas da Grande São Paulo}

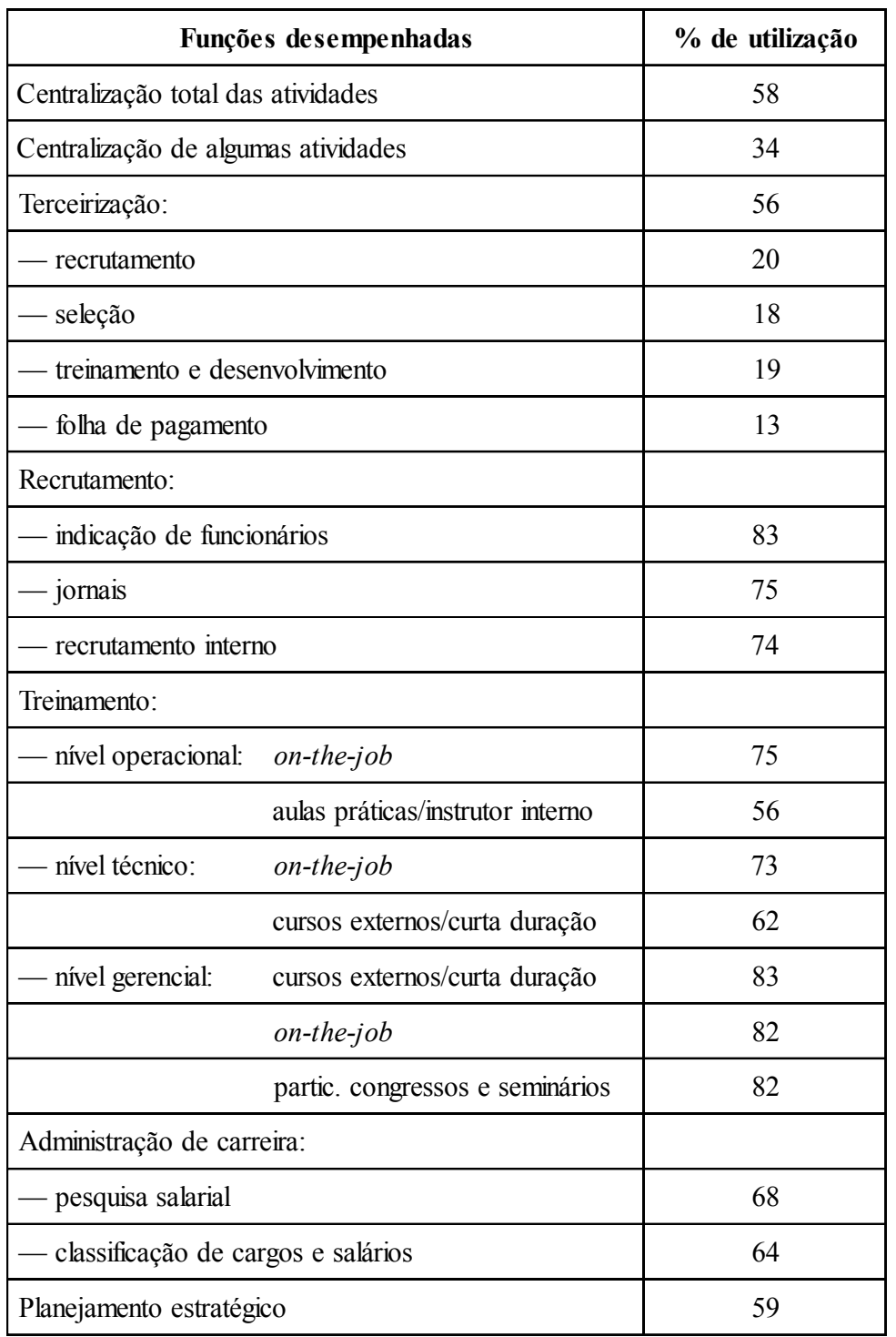


Para tentar verificar se há alguma tendência neste sentido, foram analisadas as respostas dadas às duas questões abertas dos questionários. Na primeira perguntou-se quais eram as maiores preocupações da área de RH no momento; na segunda, foi perguntado quais eram as perspectivas de mudança relacionadas à área. A análise baseou-se no conteúdo das respostas dadas, isto é, procuraramse as palavras e expressões utilizadas pelos entrevistados para definir e qualificar os problemas que estavam enfrentando. Pôde-se constatar a formação de três grupos principais, que revelavam preocupações e perspectivas de mudanças semelhantes, e que se encontravam em estágios notadamente diferentes em relação à ARH.

- O primeiro grupo, representando $28 \%$ da amostra, era composto de empresas com até 500 funcionários, predominantemente de capital nacional, com apenas duas exceções, e que possuíam ou não possuíam planejamento estratégico. As principais preocupações deste grupo referiam-se a problemas financeiros enfrentados pelas empresas, ameaçadas até mesmo na sua sobrevivência. Os entrevistados reconheciam a necessidade de implantação de políticas e sistematização da área para redução da informalidade, causa de inúmeros problemas, e de melhorar processos de produção, de se treinar mais os empregados etc. Ainda assim, o problema financeiro era um determinante e, sem a sua solução, nada seria mudado. É interessante observar que o planejamento estratégico, nesses casos, se resume nas projeções financeiras para a empresa.

. O segundo grupo, representando $19 \%$ da amostra, já havia completado uma primeira grande reestruturação da área de $\mathrm{RH}$. O grupo, composto principalmente por grandes multinacionais, com planejamento estratégico estruturado e com boa participação de RH no programa, revelou preocupações muito distintas, mostrando abordagens assaz diversificadas no pensar RH com foco no negócio para a obtenção de vantagem competitiva. A necessidade de mudar continuamente, a atenção para o cliente interno, a captação e retenção de pessoas e a determinação de competências e habilidades são outras preocupações de quase todas as empresas. A aplicação das novas técnicas também varia não pouco, entre estas empresas, desde a adoção de um misto de atividades centralizadas e descentralizadas, até a previsão de término da área de $\mathrm{RH}$, onde restariam apenas consultores para a facilitação dos trabalhos. Todas demonstram ter programas a serem implantados, ou seja, mudanças devem ocorrer em futuro próximo, porque, apesar de já terem mudado muito, consideram que ainda há muito que fazer.

. O terceiro grupo, $53 \%$ da amostra, demonstra estar em fase de transição entre os dois estágios mencionados acima. As empresas que compõem este grupo são, na maioria, grandes, mas há também algumas com menos de 500 funcionários. $\mathrm{O}$ que mais chama a atenção nas entrevistas deste grupo é que todos 
estão sintonizados com a necessidade de fazer mudanças; entretanto os entrevistados ressaltam que as mudanças já introduzidas não foram suficientes para provocar grandes impactos, e o modo como foram relatadas deixa a impressão de ausência de programação para a mudança ou de objetivos claramente definidos. Exemplo disto são empresas que implantaram programas de treinamento não atrelados a uma perspectiva de mais longo prazo; há políticas estruturadas para uma área e não há para outras; os responsáveis pela área consideram que RH precisa participar mais do planejamento e do processo decisório, que ainda precisa consolidar-se mais; alguns reconhecem ainda que, da parte da alta direção, a vontade de mudar é apenas parcial. São empresas que já passaram por reestruturações, em sua maioria, mas demonstram ter muitos problemas com motivação de pessoas, revelando uma falta de política integrada para se efetuarem mudanças.

Os três grupos identificados podem ser associados às abordagens mencionadas por Fisher (1998), citadas anteriormente. O primeiro grupo ainda está na fase operacional da $\mathrm{ARH}$; as preocupações concernem principalmente à redução de custos e sobrevivência, merecendo atenção, portanto, os problemas legais, que devem ser contornados, para não complicar ainda mais a situação destas empresas. Os entrevistados reconhecem a necessidade de mudar, mas não conseguem fazer-se ouvir, dada a premência da situação financeira da empresa. Alguns parecem bastante proativos, lutando por mais treinamento, na medida em que conseguem associar treinamento a maior produtividade; mas são ações isoladas, sem perspectivas de continuidade ou evolução.

O terceiro grupo parece estar mais relacionado à abordagem da ARH estratégica, notando-se vários estágios de desenvolvimento das áreas dentro do grupo. As empresas reconhecem a necessidade de mais investimento em RH; mas os processos tomam as mais variadas formas, demonstrando, em geral, grande dose de confusão na adoção de conceitos e na sua aplicabilidade. A sensação que fica é que há uma noção clara da necessidade de se ter e ser RH; mas o seu significado ainda está sendo trabalhado dentro de cada empresa. Algumas, por exemplo, procuram melhorar processos apenas para a obtenção de certificados ISO; em outros casos, a referência é "precisamos implantar esse RH todo", sendo a razão principal apenas porque "está todo o mundo fazendo"; ainda outros dizem que "tem de ser estratégico", sem entender bem o que está por trás dos conceitos. Essas falas retratam falta da visão quanto àquilo a que se referem Devana, Fombrun e Tichy (1984), o que torna a ação fragmentada e os processos desintegrados e demorados, nem sempre atingindo os objetivos propostos. Pode-se dizer que uma parte dessas empresas ainda está na fase reativo-defensiva descrita por Fisher (1998); mas há outras mais integradas e já sentindo a necessidade de mudar o foco dos processos de mudança. 
O segundo grupo é o que se aproxima da abordagem de ARH como vantagem competitiva. Tendo já passado por fases de reestruturação tanto da empresa como da própria área, nota-se a constante preocupação em se pensar o papel de RH dentro da empresa, o foco no negócio, no cliente interno e externo, na mudança constante e em metas de longo prazo. Aqui não se fala mais em treinamento de pessoas, mas de capacitação, qualificação e requalificação, retenção e desenvolvimento. Várias das empresas atuam em mercados muito competitivos, como o de telecomunicações e o de informática, por exemplo, reforçando a idéia de que quanto mais turbulento o ambiente, maior é a necessidade de se administrarem as pessoas para a obtenção de vantagens competitivas.

\section{Consideraçóes Finais}

A partir da análise dos modelos de gestão de recursos humanos das empresas foi possível observar dois grupos: um com um modelo de RH estratégico (53\% da amostra) e outro com um modelo de RH competitivo (19\%); mas, ainda que estas empresas possam estar configuradas dentro de um mesmo padrão, as práticas desenvolvidas apresentam grande heterogeneidade. Já que grande parte dos dados colhidos eram quantitativos, não foi possível observar se as práticas referidas tinham a qualidade necessária, para que pudessem ser incluídas verdadeiramente dentro de cada um dos modelos; portanto é possível questionar quanto as respostas refletem um comportamento para inglês ver, ou quanto correspondem a mudanças efetivas. Caldas e Wood (1997), pesquisando empresas brasileiras, mostraram que modelos ou conceitos são adotados ou por imposição das matrizes ou por pacotes de consultores, e que, na verdade, são apenas discursos da alta direção ou da gerência que não correspondem à realidade das práticas adotadas.

Por outro lado, a heterogeneidade das práticas reforça a diversidade dos conceitos apresentados pelos próprios especialistas, entrevistados nesta pesquisa. A área de gestão de recursos humanos tem sido, tradicionalmente, caracterizada por grande ambigüidade, tanto na definição de conceitos como nas suas aplicações. De fato, cabe ressaltar que os conceitos envolvidos nas práticas da gestão de recursos humanos podem ser objeto de polêmicas, que não foram consideradas no âmbito deste trabalho. A problematização desses conceitos envolve desde as práticas tradicionais da gestão de recursos humanos, até aquilo que tem sido chamado de evolução da área.

Para finalizar cabe considerar que, se a área já comporta toda esta problematização, as pesquisas existentes sobre as empresas brasileiras deveriam avançar, 
especialmente do ponto de vista qualitativo, para esclarecer como estas práticas se estão dando na realidade.

\section{Referências Bibliográficas}

\section{ALBUQUERQUE, L. G.}

O papel estratégico de recursos humanos. São Paulo, 1987. Tese (Livre Docência) - Faculdade de Economia, Administração e Contabilidade, Universidade de São Paulo.

Competitividade e recursos humanos. Revista de Administração, v. 27, n. 4, out./dez. 1992.

ANTHONY, W. P.;

PERREWÉ, P. L.;

KACMAR, K. M.

\section{Strategic} resource management. [S.1.] : Harcourt Brace \& Co, 1996.

BARBOSA, J. R.

O papel estratégico dos recursos humanos no processo de renovação organizacional, um estudo de caso : a ECT. Cadernos EBAP, 1981.

BERTERO, C. O.

A administração de recursos humanos e o planejamento empresarial. Revista de Administração de Empresas, v. 22, n. 1, p. 5-13, jan./mar. 1982.
CALDAS, M.;

WOOD, T.

For the english to see : the importation of managerial technology in late $20^{\text {th }}$ century Brazil. Organization, v. 4, n. 4, p. 517-534, 1997.

CURADO, I.;

WOOD, T.;

LINS, J.

Perfil da gestão de recursos humanos na Grande São Paulo. São Paulo : SENAC, 1995.

DEVANA, M. A.;

FOMBRUN, C.;

TICHY, N. M.

Strategic human resource management. New York : John Wiley \& Sons, 1984.

DUTRA, J. S.

Profissionais de recursos humanos - um grupo à procura de legitimação. São Paulo, 1987. Dissertação (Mestrado em Administração ) - Escola de Administração de Empresas de São Paulo, Fundação Getulio Vargas. 
Administração de carreiras : uma proposta para repensar a gestão de pessoas. São Paulo, 1993. Tese (Doutorado) - Faculdade de Economia, Administração e Contabilidade, Universidade de São Paulo.

FISHER, A. L.
A constituição do modelo competitivo de gestão de pes- soas no Brasil - um estudo so- bre as empresas consideradas exemplares. São Paulo, 1998. Tese (Doutorado) - Faculdade de Economia, Administração e Con- tabilidade, Universidade de São Paulo.

SIEHL,C.;

BOWEN, D.

The future of human resource management : March and Simon (1958) revisited. Human Resource Management, v. 36, n. 1, p. 57-63, 1997.

SPRINGER, B.;

SPRINGER, J.

HRM in the US - celebration of its centenary, In: PIEPER, R. (Ed.). Human resource management : an international comparison. New York : Walter de Gruyter, 1990.

STAEHLE, W. H.

Human resource management and corporate strategy. In: PIEPER, R. (Ed.). Human resource management : an international comparison. New York: Walter de Gruyter, 1990.

ULRICH, D.

Human resource of the future : conclusions and observations. Human Resource Management, v. 36, n. 1, p. 175179, 1997.

Os campeões de recursos humanos : inovando para obter os melhores resultados. São Paulo : Futura, 1998.

VENOSA, R.;

ABBUD, $M$.
A importância da área de re- cursos humanos segundo os principais dirigentes de Em- presas. Relatório de Pesquisa, Núcleo de Pesquisas e Publica- ções, EAESP/FGV, 1995. 